\title{
Análise dos sistemas de ancoragens e dos processos de instalação dos aparelhos aéreos circenses.
}

\section{João Gabriel B. Nunes*, Prof. Dr. Marco A. C. Bortoleto.}

\section{Resumo}

Apesar do circo vir se consolidando como objeto de estudo, ainda são poucas as investigações que analisam o risco, de forma que os problemas relativos à segurança requerem maior atenção acadêmica a fim de contribuir para uma "cultura de segurança". Este trabalho teve como objetivo analisar os tipos de ancoragens dos equipamentos aéreos de circo e debater o perfil formativo dos profissionais responsáveis. Para a realização dessa pesquisa de cunho exploratóriodescritivo foram fotografadas as ancoragens dos aparelhos aéreos de 18 estabelecimentos e um questionário semiestruturado foi respondido por 12 responsáveis pela instalação. De forma geral, vê-se uma alta diversidade de materiais e ancoragens sem uma padronização no modo de instalação e na formação dos sujeitos. Nota-se a urgência da implementação de formações específicas que supram as demandas específicas do circo.

\section{Palavras-chave:}

Circo, segurança, risco.

\section{Introdução}

O circo é uma manifestação artístico-cultural (SILVA, 2011) com diversas práticas, que vem ganhando cada vez mais destaque no cenário brasileiro e se consolidando como objeto de estudo acadêmico (ROCHA, 2010). No entanto, o risco ainda é pouco investigado (MANDELL, 2016), de forma que os problemas relativos à segurança requerem maior atenção acadêmica para, então, possibilitar uma experiência mais segura a todos os envolvidos. Com base nesse diagnóstico, o presente estudo teve como objetivo analisar os tipos de ancoragens dos equipamentos aéreos de circo em estabelecimentos localizados em cidades da Região Metropolitana de Campinas bem como debater o perfil formativo dos profissionais responsáveis.

\section{Resultados e Discussão}

Este estudo exploratório-descritivo (MARCONI \& LAKATOS, 2003) foi um estudo de campo e utilizou o método misto quali-quanti (THOMAS E NELSON, 2012) para análise de dados. Para os dados qualitativos fez-se uso da análise de conteúdo (BARDIN, 2011) enquanto para os quantitativos foi utilizada a estatística descritiva. Como instrumentos de coletas de dados foram fotografas as ancoragens dos aparelhos aéreos dos estabelecimentos visitados e um questionário semiestruturado foi respondido pelos responsáveis por essas ancoragens.

Participaram ao todo 18 estabelecimentos e foram respondidos 12 questionários sendo que dos participantes $58 \%$ são homens e $42 \%$ são mulheres com idade média de 36 anos.

Com relação as ancoragens, as estruturas na qual foram instaladas eram predominantemente treliças e vigas metálicas. Percebeu-se uma heterogeneidade na qualidade das ancoragens (dispositivos utilizados) e o uso não regular de back-up.

Notou-se também uma alta diversidade de materiais que, além permitir maior possibilidades de utilização em cada situação/contexto, sugere a necessidade de uma formação mais específica.

Ao serem questionados sobre a existência de um planejamento e uma avaliação prévia das estruturas para a instalação dos aparelhos aéreos, 83\% responderam afirmativamente.

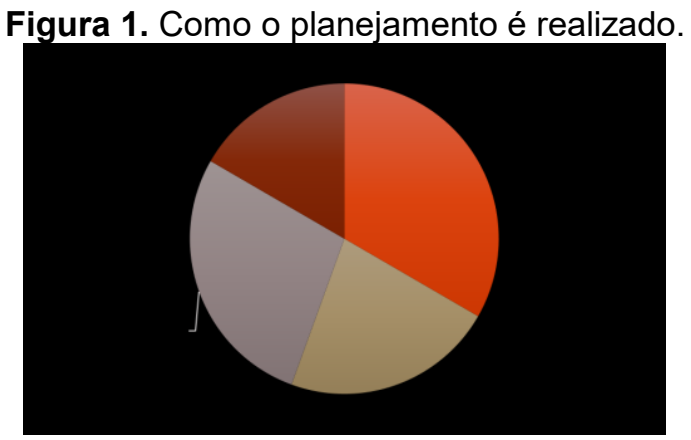

Sobre o responsável pela avaliação das estruturas, $50 \%$ alegou ser um Engenheiro Civil (único profissional com atribuição para este trabalho), $30 \%$ indicou que eles mesmos realizavam tal avaliação e $20 \%$ afirmou ser um Técnico de Segurança do Trabalho. Este fato se mostrou preocupante em virtude de que uma avaliação inapropriada pode ser tão prejudicial quanto a falta dela.

No que diz respeito à formação para a instalação de aparelhos aéreos, a maioria (67\%) reportou buscar instrução através da Norma Regulamentadora 35 que, apesar de regulamentar o trabalho em altura, raramente supre as demandas relativas as especificidades do circo.

\section{Conclusões}

O estudo sugere que, apesar da existência de um grande número de pessoas atuando com a instalação de aparelhos aéreos no circo, há uma urgência na implementação de uma política de qualificação profissional específica e que trate mais ativamente a segurança no circo.

\section{Agradecimentos}

Ao CNPq, por oportunizar a realização desta pesquisa e ao Grupo de Estudos Circus pela imensurável contribuição.

BARDIN, Laurence. Análise de conteúdo $4^{\mathrm{a} e d . ~ L i s b o a: ~ E d i c ̧ o ̃ e s, ~ v . ~ 70, ~ p ~}$ 1977, 2011.

FERREIRA, Diego Leandro; BORTOLETO, Marco Antonio Coelho; SILVA, Ermínia. Segurança no circo: questão de prioridade. Várzea Paulista, Editora Fontoura, 2015. 